\title{
A Climate Trend Analysis of Sudan
}

\section{Conclusions}

- Summer rains in western and southern Sudan have declined by 10-20 percent since the mid1970s.

- Observed warming of more than 1 degree Celsius is equivalent to another 10-20 percent reduction in rainfall for crops.

- The warming and drying have impacted southern Darfur and areas around Juba.

- Rainfall declines west of Juba threaten southern Sudan's future food production prospects.

- In many cases, areas with changing climate are coincident with zones of substantial conflict, suggesting some degree of association; however, the contribution of climate change to these conflicts is not currently understood.

- Rapid population growth and the expansion of farming and pastoralism under a more variable climate regime could dramatically increase the number of at-risk people in Sudan over the next 20 years.

\section{Food Security Context: Drying Trends in Highly Insecure Food Areas}

In 2010, approximately 8 million people faced moderate to high levels of food insecurity in northern and southern Sudan (Famine Early Warning Systems Network, 2010). These food insecure populations, primarily agro-pastoralists, tend to be located in western parts of northern Sudan (Darfur and Kordofan) or in drier portions of southern Sudan (Jonglei, East Equatoria,
Warrap, and North Bahr el Ghazal). [Please see "Objectives and Methods" for state names and populations.] This brief report, drawing from a multiyear effort by the U.S. Agency for International Development (USAID) Famine Early Warning Systems Network (FEWS NET), identifies significant reductions in rainfall and increases in temperature across these regions. These analyses are based on quality-controlled station observations, climatemodel reanalyses, and land surface-model simulations.

\section{Rainfall has Declined by 20 Percent}

Between the mid-1970s and late 2000s, summer rainfall decreased by 10-20 percent across parts of western and southern Sudan, placing already food insecure populations at greater risk. These declines can be visualized in three ways: as a contraction of the region receiving adequate rainfall for viable agricultural livelihoods, as a map of anticipated changes in rainfall, and as time-series plots of selected regions.

Sudan receives most of its rain between June and September, and rainfall totals of more than 500 millimeters $(\mathrm{mm})$ during this season typically provide enough water for farming and livestock. Between 1960 and 1989, the region receiving (on average) this much rain or more was vast, over 858,000 square kilometers $\left(\mathrm{km}^{2}\right)$ - an area the size of France and the United Kingdom combined. This region is shown in light brown in the left panel of

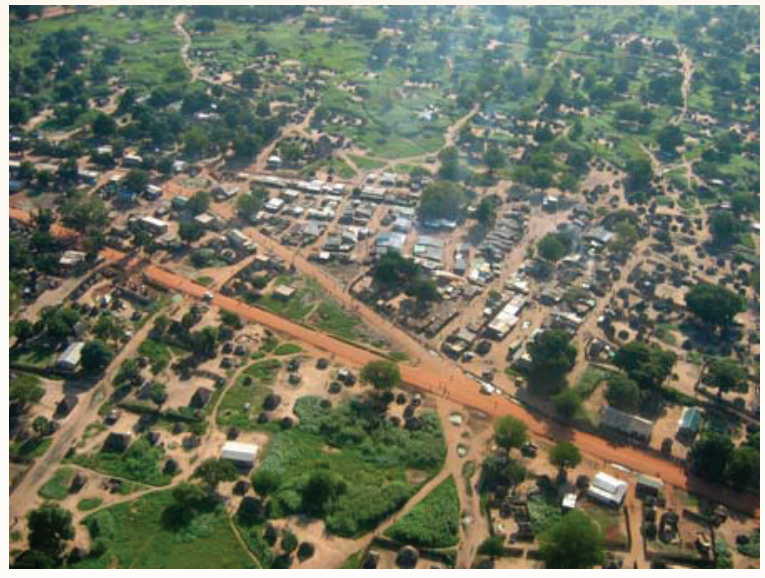

Juba, Southern Sudan, from the air. 
figure 1 and should be understood to lie beneath the dark brown and orange areas. Over the past 20 years, this region has contracted (dark brown polygon), exposing populations in Darfur, Kordofan, Upper Nile, Jonglei, and East Equatoria to increased rainfall deficits. In the west, this contour shifted from approximately 11 degrees north to 10 degrees north. In the Upper Nile, the shift was even more drastic from approximately 11 degrees north to 9 degrees north. A third westward retraction is occurring in Jonglei and East Equatoria, with the $500 \mathrm{~mm}$ contour shifting from approximately 33 degrees east to 32 degrees east.

If present rainfall trends continue, by 2025 the drying impacts likely will reach into West and North Bahr Al Ghazal, Warrap, Unity, Central Equatoria, and Al Buhairat (fig. 1, orange polygon); an area with a total population of 4.1 million. The area receiving more than $500 \mathrm{~mm}$ of rainfall could shrink by $249,000 \mathrm{~km}^{2}$ (30 percent of the 1960-89 area), leaving a large number of people exposed to increased food insecurity and impacting crop production in the southeastern part of the country.

Rainfall reductions can be visualized by combining the observed 1960-2009 changes with predicted 2010-39 changes, based on persistence of the observed trends (fig. 2, top panels). Rainfall declines range from -150 to $-50 \mathrm{~mm}$ across the western and southern portions of the country, large numbers for a drought-prone country. Observed changes alone account for 63 percent of the change magnitudes. South Darfur exhibits the largest declines, followed by Blue Nile and West Equatoria. These reductions in rainfall appear most likely to affect the insecure areas around the cities of Al Fāshir, Nyala, and Wāu (fig. 1).

Smoothed time series (fig. 2, middle and lower panels, 5-year running means) of 1900-2009 rainfall, extracted for the extended Darfur region (10 to 16 degrees north, 22 to 29 degrees east) and southern Sudan ( 3 to 7 degrees north, 27 to 35 degrees east), show that 1990-2009 rainfall has been, on average, about 20 percent lower (-1 standard deviation) than rainfall between 1900 and 1989 .

\section{Much Warmer Air Temperatures}

Temperatures have increased by more than 1 degree Celsius $\left({ }^{\circ} \mathrm{C}\right)$ across much of central and southern Sudan. As with rainfall, these changes can be visualized as expansions of hot (and in this case dry) areas, as maps of anticipated changes, or as time series. Figure 1 (right panel) shows warming in Sudan as successive advances of the average temperatures, represented here by the $30^{\circ} \mathrm{C}$ contour line. Areas of Sudan warmer than $30^{\circ} \mathrm{C}$ correspond with regions of sparse vegetation and low rainfall. These warm areas have advanced southward,

\section{A. Rainfall}

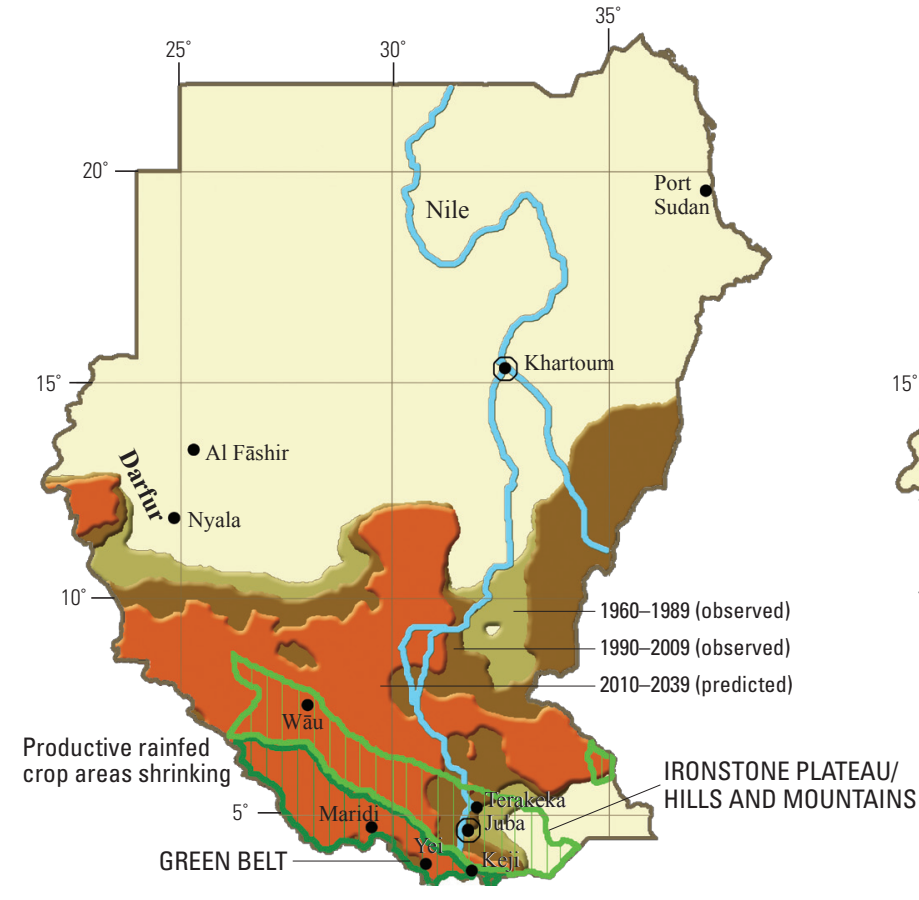

\section{B. Temperature}

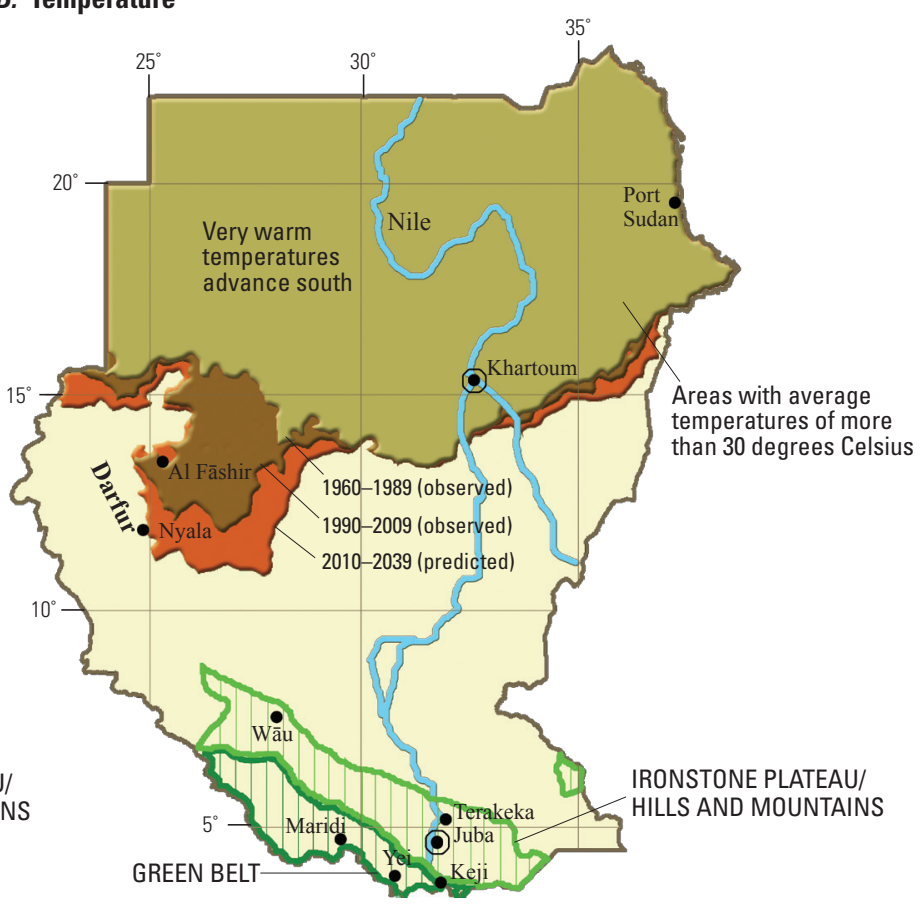

Figure 1. Climate change in Sudan. A, Average location of the 500-millimeter rainfall isohyets for the years 1960-1989 (light brown), 19902009 (dark brown), and 2010-2039 (predicted, orange). The green polygons in the foreground show the main crop surplus region (the Green Belt livelihood zone) and the agro-pastoral Ironstone Plateau and Hills and Mountains livelihood zones. $B$, Similar changes for the 30 degrees Celsius isotherm. Areas north of this line are very hot; this intense heat makes plant growth and pastoral livelihoods difficult. 


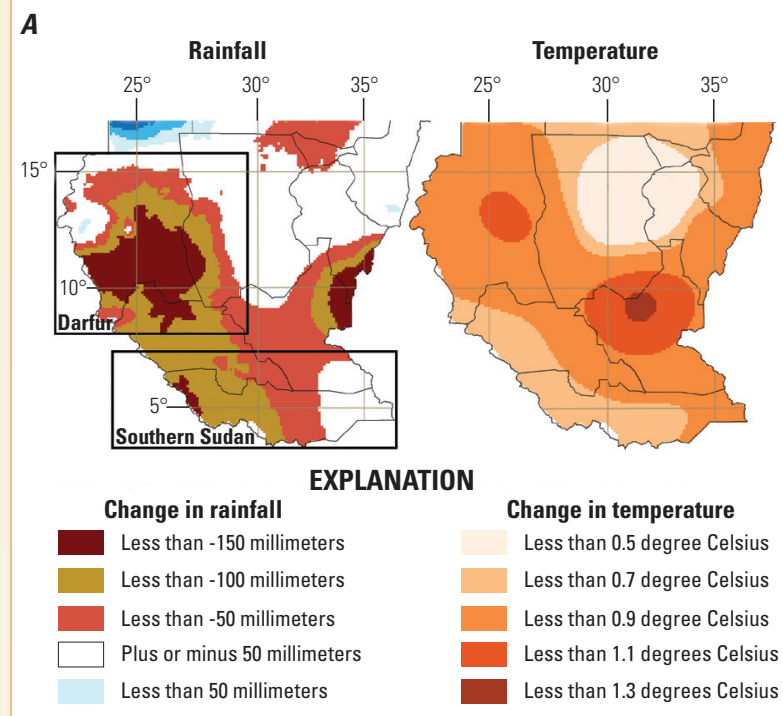

B

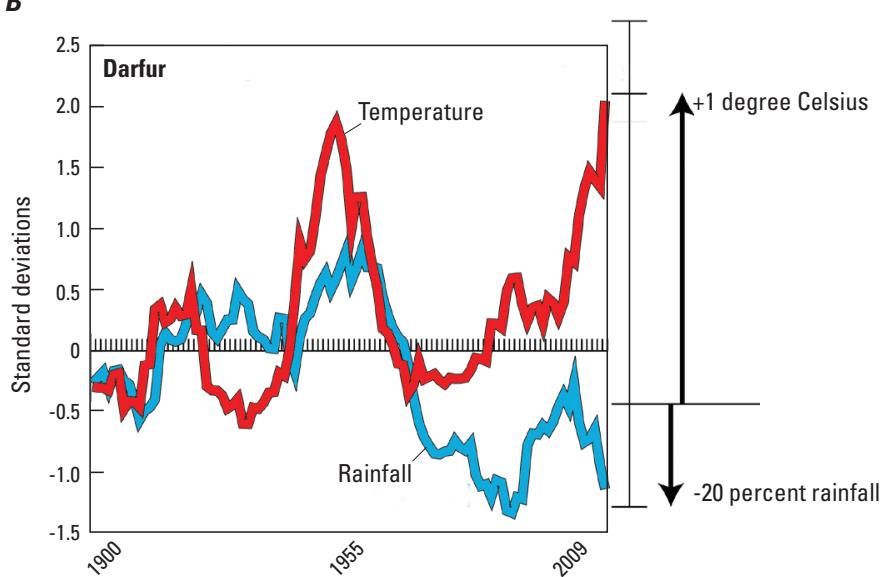

C

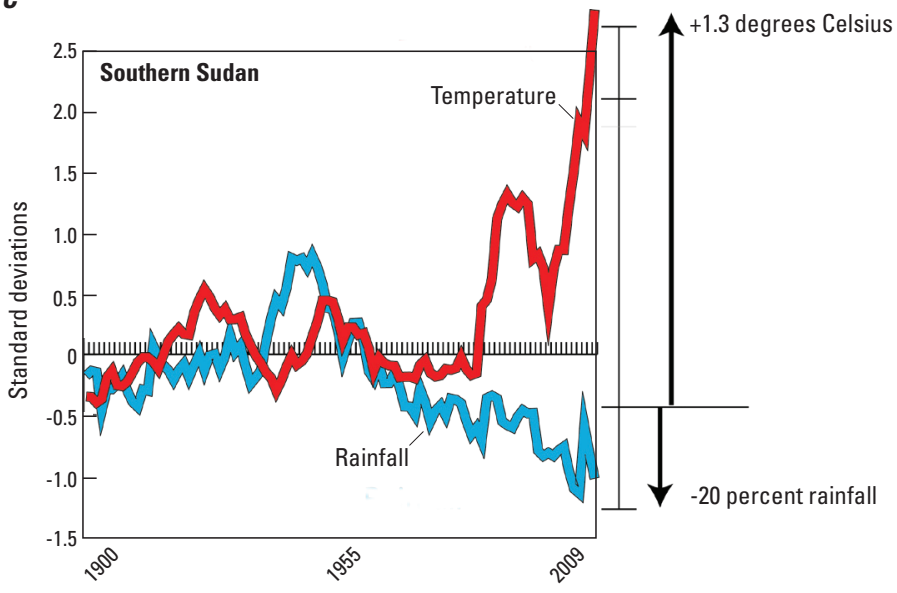

Figure 2. Observed and projected change in rainfall and temperature. $A$, Together with smoothed rainfall and air temperature time series, $B$, for the extended Darfur region (10-16 degrees north, 22-29 degrees east), and $C$, for southern Sudan (3-7 degrees north, 27-35 degrees east). especially in the vulnerable areas surrounding Al Fāshir and Nyala. This transition to an even warmer climate has strong food security implications, reducing crop harvests and pasture availability, and amplifying the impact of droughts in this conflict torn area.

Over the past 30 years, central and southern Sudan have been among the most rapidly warming locations on the globe, with station temperatures increasing as much as $0.4^{\circ} \mathrm{C}$ per decade. Assuming these trends persist, a composite can be created of observed and anticipated air temperature changes (fig. 2, top right panel). Again, observed changes alone account for 63 percent of the change magnitudes. The spatial pattern of warming corresponds (broadly) with the areas associated with reduced precipitation. Western and southern Sudan are becoming drier and hotter, which is consistent with an increase in atmospheric circulation bringing dry subsiding air (Please see "Objectives and Methods" section for background information) during the main rainy season (June-September).

Time series of air temperature data (fig. 2, middle and lower panels, 5-year running means) show that the magnitude of recent warming is large and unprecedented within the past 110 years. It was estimated that the 1975 to 2009 warming was more than $1.3^{\circ} \mathrm{C}$ for southern Sudan and more than $1{ }^{\circ} \mathrm{C}$ within the extended Darfur region. Given that the standard deviation of annual air temperatures in these regions is approximately $0.5^{\circ} \mathrm{C}$, these increases represent a very large $(2+$ standard deviations) change from the climatic norm. Such warming, in regions with very high average air temperatures, can amplify the impact of water shortages on agriculture.

\section{Temperature Increases Intensify the Impact of Droughts}

Under normal growing conditions, with plenty of available water, energy from the sun causes evaporation of water from the soil and transpiration of water vapor from leaves. The combination of these two flows of water vapor is called evapotranspiration. Year-to-year variations in evapotranspiration are strongly related to changes in plant growth, cereal formation and filling, end-of-season yields, and pasture biomass. Increasing air temperatures, especially in very warm regions, can reduce evapotranspiration. As already high temperatures rise, the environment becomes less hospitable to plants. These warming effects can combine with decreases in rainfall to reduce evapotranspiration and crop yield. Over the past 20 years, declines in evapotranspiration (fig. 3) are larger for the extended Darfur region (approximtely -40 percent) and southern Sudan (approximately -28 percent) than the associated decreases in rainfall (approximately -10 percent). Temperature impacts appear to be amplifying the effects of drought. 

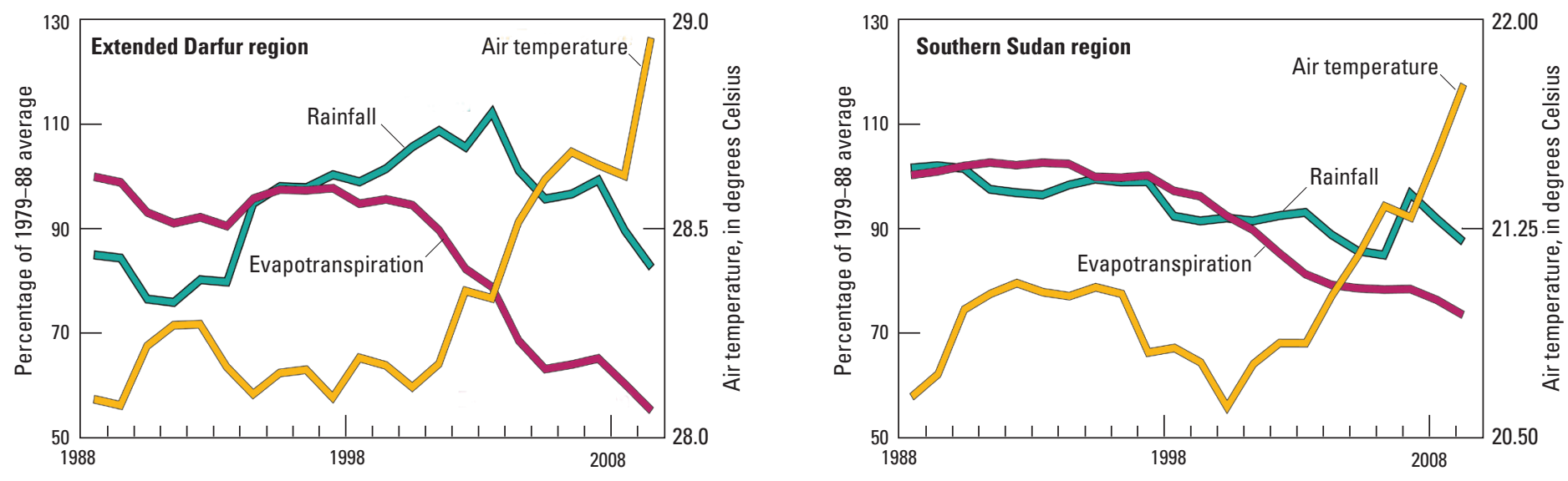

Figure 3. Smoothed time series of June through September rainfall, actual evapotranspiration, and average air temperature for the extended Darfur region and the southern Sudan region.

While limitations inherent in the available data and models make all the estimates uncertain, both simple plots based on available station data (fig. 2) and results from sophisticated land-surface models (fig. 3) tell a similar story; western and southern Sudan are experiencing substantially warmer and drier weather, and the combination of these effects is reducing evapotranspiration and producing more frequent droughts.

\section{Convergence of Evidence}

The results presented here point to a convergence of evidence among multiple datasets. The station-based analyses of rainfall and temperature show large departures from normal, with both drier and warmer conditions in western and southern Sudan. Further evidence of these observed changes comes from nearby southwestern Ethiopia. FEWS NET has analyzed observations from Ethiopian rain gage stations, and these studies reveal similar trends (see section "Objectives and Methods"). In addition, the evapotranspiration data come from another independent source-land-surface model results downloaded from the Global Land Data Assimilation System. All results point to substantial recent drying and warming.

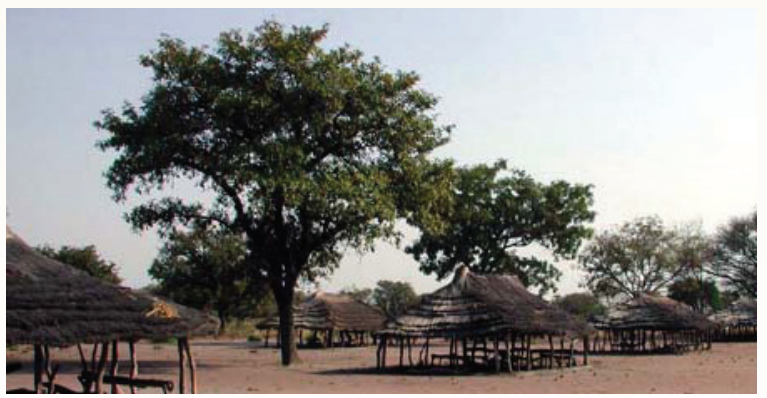

\section{Some Implications for Food Security and Adaptation}

The data shown here depict drying trends in one of the world's most food insecure regions. The extended Darfur region and southern Sudan have experienced considerable rainfall declines since the $1960-89$ period. The dryness in the south is consistent with previous FEWS NET studies (see section "Objectives and Methods") identifying large declines in June-September rainfall in southern Ethiopia. A -1 standard deviation decline in rainfall (close to -20 percent) is sufficient to markedly increase the number of expected poor harvests. Increasingly frequent droughts might be offset by improved water- and agricultural-management practices, and raising yields in wetter areas may be a more viable option than extending agriculture into more marginal areas. In both cases, however, rapid population growth may make it difficult to slow the process of agricultural extensification into marginal areas.

Since 1980, decreasing rainfall has been accompanied by rapid increases in air temperature on the order of more than $1^{\circ} \mathrm{C}$. This warming, which is two and a half times greater than global warming, is reducing evapotranspiration and making normal years effectively drier, especially in the extended Darfur and southern Sudan regions.

\section{Objectives and Methods}

The FEWS NET Informing Climate Change Adaptation series seeks to guide adaptation efforts by providing high quality subnational analyses of recently observed climate trends. For development and food security decision makers, knowing whether these observed trends are 
related to natural climate variations, global warming, or some combination of the two is less important than knowing now where to focus adaptation efforts.

These FEWS NET reports rely on rigorous analysis of station data, combined with attribution studies using observed climate data. This brief report examines Sudan rainfall and temperature trends over the last 110 years (1900-2009) using observations from 110 rainfall gages and 36 air temperature stations for the main summer rainy period, corresponding to June through September. The data were quality controlled, converted into 19602009 trend estimates, and interpolated using a rigorous geo-statistical technique (kriging). Kriging produces standard error estimates, and these can be used to assess the relative spatial accuracy of the identified trends. Dividing the trends by the associated errors allows the relative certainty of estimates to be identified (Funk and others, 2005; Verdin and others, 2005; Brown and Funk, 2008; Funk and Verdin, 2009).

The observed warming trends are more likely to continue than the rainfall trends. But recent declines in rainfall appear linked to a warming of the Indian Ocean and, therefore, likely to persist at least for the next decade. Readers interested in more information can see the reference links below. These publications are available at http://earlywarning.usgs.gov/adds/reports.php.

In addition to climate data, FEWS NET analyses also integrate demographic, vulnerability, livelihood, and agricultural information. These information sources allow the evaluation of the potential consequences of climate trends within the broader context of the region's human geography and food economy. For Sudan, warming and drying in the densely populated area of the country (fig. 4) may place large vulnerable populations at risk.

\section{References}

Brown, M.E., and Funk, C.C., 2008, Food security under climate change: Science, v. 319, p. 580-581. (Also available at ftp://chg.geog.ucsb.edu/pub/pubs/Science_2008.pdf.)

Famine Early Warning Systems Network, 2010, Food security framework, available at $h t t p: / / w w w . f e w s . n e t / m l / e n / i n f o /$ Pages/fmwkfactors.aspx?g $b=s d \& l=e n \& l o c=2$.

Funk, C., Eilerts, G., Davenport, F., and Michaelsen, J., 2010, A climate trend analysis of Kenya-August 2010: U.S. Geological Survey Fact Sheet 2010-3074, 4 p. (Also available at http://pubs.usgs.gov/fs/2010/3074/pdf/fs2010-3074.pdf.)

Funk, C., Senay, G., Asfaw, A., Verdin, J., Rowland, J., Korecha, D., Eilerts, G., Michaelsen, J., Amer, S., and Choularton, R., 2005, Recent drought tendencies in Ethiopia and equatorial-subtropical eastern Africa: U.S. Agency for International Development, Washington, D.C. (Also available online at ftp://chg.geog.ucsb.edu/pub/pubs/FEWSNET_2005.pdf.)

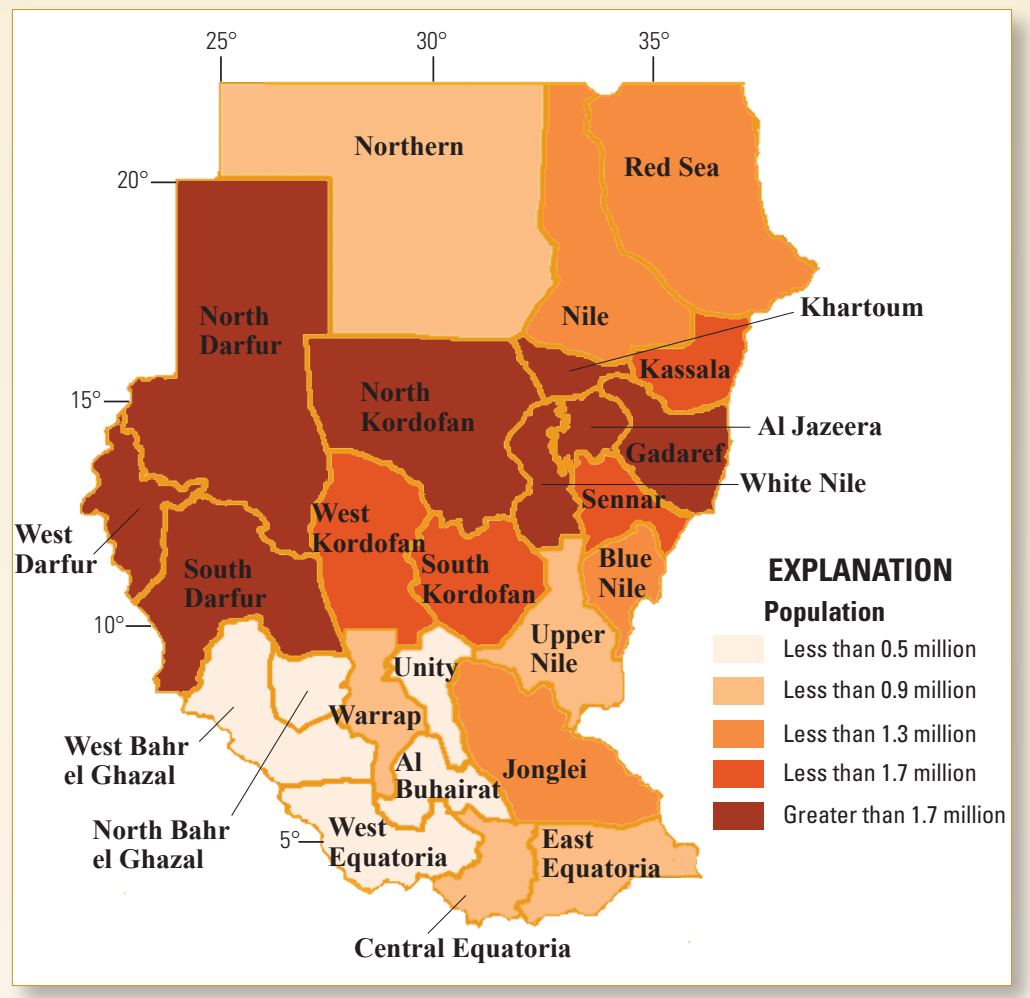

Figure 4. 2008 census data for Southern Sudan and Landscan 2007 population for Northern Sudanese states (http://www.populationexplorer.com).

Funk, C., Dettinger, M.D., Michaelsen, J.C., Verdin, J.P., Brown, M.E., Barlow, M., and Hoell, A., 2008, Warming of the Indian Ocean threatens eastern and southern African food security but could be mitigated by agricultural development: Proceedings of the National Academy of Sciences of the United States of America, v. 105, no. 32, p. 11,081-11,086. (Also available online at ftp://chg.geog.ucsb.edu/pub/pubs/ PNAS_2008.pdf.)

Funk, C.C., and Brown, M.E., 2009, Declining global per capita agricultural production and warming oceans threaten food security: Food Security, v. 1, no. 3, p. 271-289. (Also available online at ftp://chg.geog.ucsb.edu/pub/pubs/ FoodSecurity_2009.pdf.)

Funk C., and Verdin, J.P., 2009, Real-time decision support systems - The famine early warning system network, in Gebremichael, M., and Hossain, F., eds., Satellite Rainfall Applications for Surface Hydrology: Netherlands, Springer, p. 295-320. (Also available online at ftp://chg.geog.ucsb.edu/ pub/pubs/RealtimeDSS_for_FEWS_NET_final.pdf.)

Verdin, J.P., Funk, C.C., Senay, G.B., and Choularton, R., 2005, Climate science and famine early warning: Philosophical Transactions of the Royal Society B-Biological Sciences, v. 360 , no. 1,463 , p. $2,155-2,168$. (Also available online at ftp://chg.geog.ucsb.edu/pub/pubs/RoyalSociety_2005.pdf.)

Williams, A.P., and Funk, C.C., 2011, A westward extension of the warm pool leads to a westward extension of the Walker circulation, drying eastern Africa: Climate Dynamics, in

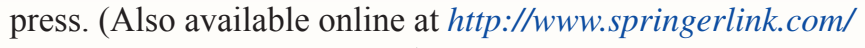
content/u0352236x6n868n2/.) 


\section{The Climate Change and Conflict Link}

A lively debate exists about the nature and strength of a presumed link between climate change and conflict in Sudan. This is especially true about Darfur, where the central role of natural resources in a high-profile conflict dynamic are well-established, and climate change is often assumed to be a key cause. At the usual national or subnational scale of studies of this climate change and conflict link, the debate most often centers on fairly coarse resolution pictures of the livelihoods involved in the conflict (pastoralists and farmers) and the specific local expressions of the climate change conceived to be driving the conflict (warmer and drier). Applying coarse, dimensionless patterns of climate stress to a broad and overly generalized picture of the human livelihoods may fail to provide a rigorous analytic structure to inform the global debate on the threats and impacts of climate change and actionable insights on climate-related adaptive measures that could be useful in conflict-affected areas such as Darfur. In Southern Sudan, the conflict seems to become increasingly apparent in Warrap, the Lakes area, and near the border between Ironstone and the western flood plains.

The "upscaled" and nationally-derived climate change information provided here, allied with the high-resolution livelihood information already available for Sudan, offers a potentially rich new opportunity. By observing and assessing the actual and expected future interactions of climate change with highly resolved pictures of livelihood-related grievances and forces promoting conflict in specific communities, emergent conflict areas may be better identified.

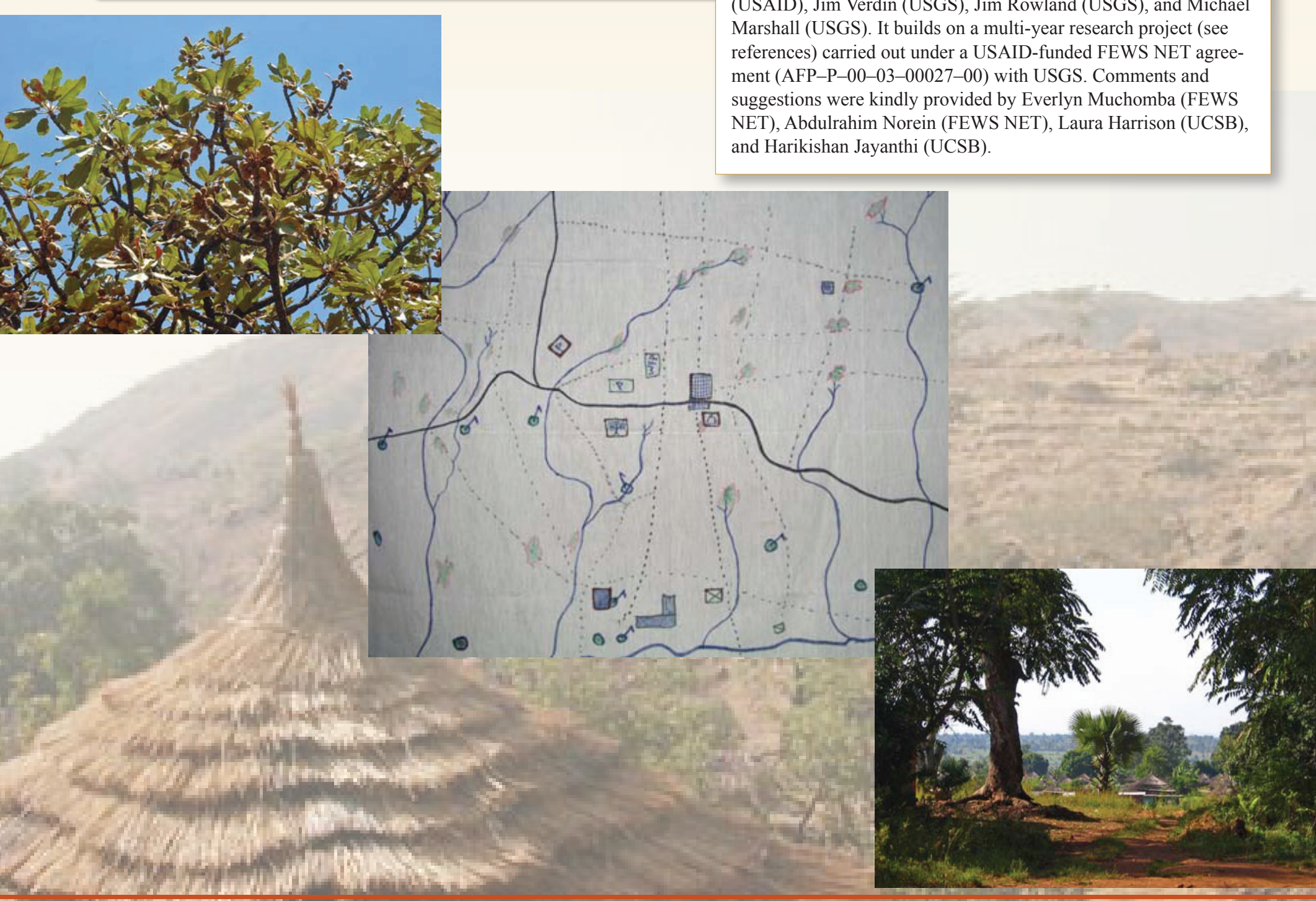

This report was written by Chris Funk (USGS), Gary Eilerts (USAID), Jim Verdin (USGS), Jim Rowland (USGS), and Michael Marshall (USGS). It builds on a multi-year research project (see references) carried out under a USAID-funded FEWS NET agreement (AFP-P-00-03-00027-00) with USGS. Comments and suggestions were kindly provided by Everlyn Muchomba (FEWS NET), Abdulrahim Norein (FEWS NET), Laura Harrison (UCSB) and Harikishan Jayanthi (UCSB). 